\title{
ESCOLA E FORMAÇÃO DE PROFESSORES: PROBLEMATIZAÇÃO E INVESTIGAÇÃO SOBRE O TRABALHO DOCENTE NO PIBID
}

\author{
CAMPELO, Talita da Silva ${ }^{1}$
}

\begin{abstract}
RESUMO
O artigo decorre de uma pesquisa que investigou os diferenciais da parceria universidade escola básica para a formação inicial de pedagogos docentes no contexto do Programa de Bolsa de Iniciação à Docência (PIBID) proposto pela CAPES. Metodologicamente, foi desenvolvido um estudo de caso sobre o PIBID Pedagogia de uma universidade federal do Rio de Janeiro. Os dados, construídos e analisados com base em Zeichner e Cochran-Smith e Lytle, sugerem que, especialmente pelo papel desenvolvido pelo professor supervisor da escola parceira, o PIBID potencializa a aprendizagem da docência dos licenciandos bolsistas. Essa aprendizagem se expressa no desenvolvimento de uma postura investigativa.
\end{abstract}

Palavras-Chave: Pedagogos docentes - PIBID - Parceria universidade-escola básica - Professor-Supervisor - Investigação como postura.

\begin{abstract}
The article stems from a research investigation which focuses on a differential partnership between university - basic school for the initial training of teachers in the context of a Scholarship Program for Teaching (PIBID) proposed by CAPES. Methodologically, we developed a case study at the PIBID Education program which was linked to the Federal University of Rio de Janeiro. The data was constructed and analyzed based on Zeichner and Cochran-Smith and Lytle. Findings suggest that, especially, the role played by supervisor teachers from the partner school enhances the learning/ maturation of the undergraduate students. This learning process is expressed in development of an investigative procedure.
\end{abstract}

KeYwORDS: Teaching Pedagogue - PIBID - University-basic school partnership - Supervisor teacher in basic school - Investigative procedure.

\footnotetext{
${ }^{1}$ Doutoranda pelo Programa de Pós-graduação em Educação da Universidade Federal do Rio de Janeiro. Email: talitacampelo@gmail.com
} 


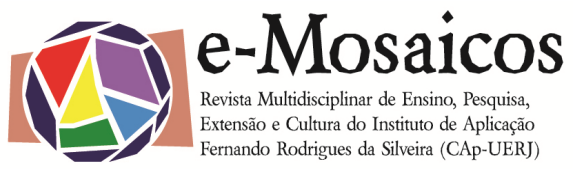

\section{INTRODUÇÃO}

Este artigo apresenta os resultados de um estudo de caso que analisa os diferenciais da parceria universidade - escola básica para a formação inicial de pedagogos docentes no contexto do PIBID (Programa Institucional de Bolsas para Iniciação à Docência). Nosso interesse são as relações de ensino/aprendizagem sobre a docência que se estabelecem, no contexto do programa, entre professores experientes na escola básica e professores em formação inicial. Nesse sentido, está centrada nas ações do programa que se desenvolvem a partir das mediações e intervenções das professoras supervisoras.

Integrante do Plano Nacional de Formação de Professores (2009), o PIBID é um programa brasileiro de iniciação à docência que visa a participação de licenciandos em atividades de ensinoaprendizagem desenvolvidas na escola pública. O programa é desenvolvido por meio da concessão de bolsas de iniciação à docência para estudantes, bolsas de coordenação para professores coordenadores (Instituições de Ensino Superior) e bolsas de supervisão para professores supervisores (Escola Básica). Seu lançamento ocorreu em dezembro de 2007, mediante Edital MEC/CAPES/FNDE $01 / 2007^{2}$.

Os licenciandos são envolvidos, ao longo de sua participação no programa, no processo de planejamento e desenvolvimento de atividades de aula, materiais didáticos e projetos interdisciplinares em ciclos contínuos (não há limitações de tempo para permanência dos licenciandos no programa). Tudo isto é feito coletivamente com professores supervisores (da escola básica) e professores coordenado-

2 MEC - Ministério da Educação. CAPES Coordenação de Aperfeiçoamento de Pessoal de Nível Superior. FNDE - Fundo Nacional de Desenvolvimento da Educação. res (da universidade). Estas características distintas do programa certamente imprimem mudanças na formação dos licenciandos que dele participam.

Concentrando-nos no PIBID Pedagogia de uma universidade federal do Rio de Janeiro nos interessa analisar o trabaIho desenvolvido pelas professoras supervisoras com os licenciandos participantes do programa e compreender como se desenvolvem as intervenções das professoras supervisoras investigadas no processo de formação docente desses licenciandos. Quais as contribuições do papel desenvolvido pelas professoras supervisoras do PIBID Pedagogia para a formação inicial do pedagogo docente na perspectiva da parceria universidade - escola básica?

Metodologicamente, desenvolvemos um estudo de caso único (holístico), com base nos pressupostos de André (2005 e 2013) e Yin (2010). O caso se forja na especificidade do PIBID Pedagogia da instituição investigada, cuja prática requer que os bolsistas façam etnografia da prática escolar, se inserindo na turma semanalmente como copartícipe dela, indo além da proposta de desenvolver atividade de ensino em tempo específico, o que requer um convívio prolongado de aprendizagem sobre a docência sob a intervenção da professora supervisora.

André (2005) sinaliza que o estudo de caso ressurge na pesquisa educacional com um sentido mais abrangente: o de focalizar um fenômeno particular, levando em conta seu contexto e suas múltiplas dimensões. Valoriza-se o aspecto unitário, mas ressalta-se a necessidade da análise situada e em profundidade. Assim, o mundo do sujeito, os significados que atribui às suas experiências cotidianas, sua linguagem, suas produções culturais e suas formas de interações sociais constituem os núcleos centrais de preocupação dos pesquisadores. Se a visão de realidade é construída pelos sujeitos, nas interações sociais vivenciadas em seu cotidiano, tor- 
na-se fundamental uma aproximação do pesquisador a essas situações (ANDRÉ, 2005).

Preocupados com isto optamos por uma imersão em campo de um ano, durante a qual foram feitas observações, entrevistas e análise documental. Neste período construímos evidências no contato direto com os sujeitos envolvidos no projeto: 1 professora coordenadora (universidade), 5 professoras supervisoras (escolas parceiras) e 14 licenciandos bolsistas.

Para análise e interpretação dos dados nos utilizamos de uma estratégica analítica geral (YIN, 2010) voltada para o exame, a categorização, a tabulação, o teste ou nas evidências recombinadas de outra forma, para tirar conclusões baseadas empiricamente. Para isso foram usados um dos quatro eixos propostos por Yin (2010): o exame dos dados a partir das proposições teóricas. Foram usadas também técnicas específicas da análise dos estudos de caso propostas pelo autor, como a combinação de padrão, a construção da explanação e a síntese cruzada dos dados.

Para fundamentar nosso estudo, nos apoiamos em três autores: Zeichner (2010), Cochran-Smith e Lytle (1999). Nossas proposições teóricas decorrem do estudo sobre dois eixos: relação teoriaprática e parceria universidade-escola básica. Direcionamo-nos ao desenvolvimento de terceiros espaços como facilitadores da articulação entre as dimensões teóricas e práticas do conhecimento sobre a docência (ZEICHNER, 2010), e de igual modo, às concepções de formação de professores que preveem a troca de saberes entre docentes experientes e em formação inicial (COCHRAN-SMITH e LYTLE, 1999).

No entanto, estar com professores experientes e passar mais tempo na escola não parece ser suficiente para melhorar a formação docente em uma perspectiva de superar a distância entre a formação e o trabalho (COCHRAN-SMITH e LYTLE, 1999; ROLDÃO, 2007; ZEICHNER, 2010). Nesse sentido, o diferencial de espaços híbridos - terceiros espaços - para a formação inicial de professores se materializa quando, para além de grupos de encontro, estes se configuram como "comunidades intelectuais, sociais e organizacionais que dão suporte a aprendizagem de professores, promovendo oportunidades para que pensem, falem, leiam e escrevam sobre seus trabalhos diários, de maneira intencional e planejada." (COCHRAN-SMITH e LYTLE, 2002).

Nessa perspectiva, consideramos o PIBID como um espaço propício para uma conexão entre universidade e escola básica que afirme a relação indissociável entre teoria e prática, por se basear em uma imersão orientada na escola que possibilita aos licenciandos construir conhecimentos sobre a docência em experiências mediadas tanto por professores da universidade quanto por professores da escola básica, interligando, através da problematização e da reflexão, conhecimentos acadêmicos e práticos. É na análise destes aspectos do PIBID que focalizaremos este trabalho.

Conforme o termo de consentimento assinado pelos sujeitos da pesquisa, a identidade de todos os envolvidos será preservada. Para fins de organização foram utilizados codinomes para os licenciandos bolsistas e para os supervisores. Quanto aos licenciandos bolsistas, eles serão referenciados pelo termo "pibidianos" em respeito à autodenominação do grupo.

\section{ESCOLA, PROFESSORES E CONSTRUÇÃO DE CONHECIMENTO SOBRE A DOCÊNCIA: A INVESTIGAÇÃO COMO POSTURA}

Moreira (2001) aponta a necessidade dos currículos para formação de professores se voltarem para o desenvolvimento das dimensões investigativas e reflexivas. 
Para o autor, o professor com esse tipo de formação é aquele que é:

o mais capaz de desenvolver formas alternativas de pedagogia que privilegiem a luta pela inclusão e formular (...) um novo sentido para a desgastada noção de cidadania, a partir de currículos que acolham as diferenças identitárias que marcam os indivíduos e os grupos sociais e, ao mesmo tempo, constituam espaços em que se ensinem e aprendam os conhecimentos e as habilidades necessárias à transformação das relações de poder que socialmente produzem e preservam tais diferenças (Moreira, 2001, p.12).

Ainda segundo o autor, é esse professor e são esses currículos que se fazem indispensáveis nas escolas e salas de aula das sociedades multiculturais contemporâneas, tão marcadas pelos efeitos letais do neoliberalismo e de um processo de globalização excludente, evidentes no estado de angústia, desespero, desesperança, ódio, medo e violência que prevalece em todos os grupos cujas vozes vêm sendo silenciadas e cujos direitos vêm sendo flagrantemente desrespeitados (MOREIRA, 2001).

Aqui, nos utilizamos de três pontos propostos por Moreira (2001) para defender a importância de formar professores que sejam intelectuais que refletem e investigam a própria prática. Em primeiro lugar, isto permite que se repense o trabaIho docente, oferecendo a base teórica necessária para considerar o trabalho docente como intelectual e não apenas técnico. Em segundo lugar, é útil na medida em que procura definir as condições necessárias para que o professor funcione como intelectual. Em terceiro lugar, sugere ao professor lutar pela concretização dessas condições.

Ainda segundo Moreira (2001) tanto a prática profissional como o preparo do professorado precisam combinar dimensões de ordem política, cultural e acadêmica. Essa perspectiva instiga o professor a assumir-se como intelectual, de modo a evidenciar: o compromisso com lutas particulares no contexto em que atua, e, ao mesmo tempo, com a construção de uma sociedade menos opressiva; o permanente propósito de mostrar, por meio da crítica cultural, que as coisas não são inevitáveis; a preocupação em fazer avançar o conhecimento e a liberdade; bem como o empenho em auto-aperfeiçoar-se e aperfeiçoar sua prática.

Para tanto, se faz necessário que a formação inicial docente equilibre momentos em que se pensa, se faz e se pensa sobre o que se faz, projetando nos futuros professores modelos de práticas baseadas em investigação e reflexão. A ideia é que se preserve a preocupação com os aspectos políticos, sociais e culturais em que se insere a prática, se leve em conta todos os silêncios e todas as discriminações que se manifestam na sala de aula, bem como amplie o espaço de discussão da atuação docente.

Por este caminho, Zeichner (2010) aponta para a necessidade de se repensar a formação dos professores em uma perspectiva que integre escola e universidade conectando melhor os conhecimentos sobre a docência que são construídos em ambos os espaços. A partir do conceito de "terceiro espaço", o autor propõe três estratégias de enfrentamento dessa problemática: participação de professores da educação básica e de seu conhecimento nas disciplinas acadêmicas e nas experiências de campo; incorporação de representações das práticas dos professores da escola básica nos cursos das universidades; e na realização de uma parte ou a totalidade das disciplinas de metodologia dos cursos universitários em escolas do ensino fundamental e médio.

Em qualquer das proposições apresentadas por Zeichner (2010) há um es- 
forço deliberado para conectar estrategicamente conhecimento acadêmico e conhecimento da prática profissional em vista de um melhor acompanhamento da aprendizagem dos professores em formação acerca de como desenvolver práticas de ensino específicas defendidas nos cursos de metodologia. A ideia central é a de reflexão sobre o trabalho docente entre pares: professores em formação inicial e professores experientes.

Para Cochran-Smith e Lytle (2002), é imprescindível que se criem grupos sociais de professores em formação, iniciantes e experientes que se juntem com o tempo, pelo propósito de obter novas informações, reconsiderar crenças e conhecimentos prévios e construir suas próprias ideias e experiências, assim como de outros, a fim de trabalhar com uma intenção específica de melhorar a prática e a aprendizagem de estudantes em escolas.

Nesse sentido, tão importante quanto investigar a docência é investigar a docência coletivamente, entendendo que se aprende mais e melhor sobre o trabalho docente quando os professores - investigadores/investigados - expõem o que fazem dentro das salas de aula. Sobre isso, Nóvoa (2009, p.15) enfatiza a necessidade de "devolver a formação de professores aos professores, porque o reforço de processos de formação baseados na investigação só faz sentido se eles forem construídos dentro da profissão". Nessa perspectiva, os terceiros espaços e as comunidades de aprendizagem docente são de muita importância para 0 ensino/aprendizagem da docência. A criação de ambientes - físicos ou não - em que professores em formação inicial e professores já atuantes na escola básica possam pensar juntos sobre o trabalho docente é profícuo para o desenvolvimento de uma postura investigativa.

Segundo Cochran-Smith e Lytle (1999), a investigação como postura, como construto para entender o aprendizado de professores, baseia-se em uma concepção mais rica de conhecimento que as permitidas pela tradicional distinção conhecimento formal/conhecimento prático. Trata-se de uma concepção mais rica de prática que a sugerida no aforismo que a prática é prática, uma concepção mais rica de aprendizado ao longo da história de vida profissional que o conhecimento de especialização e uma concepção mais rica de culturas e propósitos educacionais que as difundidas por muitas reformas escolares. Nesse sentido, a postura investigativa não segue a distinção entre conhecimento formal e conhecimento prático; enfatiza, isto sim, a importância do conhecimento local $^{3}$ que também pode ser útil em contextos mais amplos.

A reflexão é parte da investigação, e não pode haver uma postura investigativa sem ser reflexivo, mas é possível ser reflexivo sem fazer investigação. Assumir a investigação como postura é mais do que ser um "professor-reflexivo" porque "as pessoas que desenvolvem a investigação como postura sobre a própria prática, estão sendo reflexivas, mas a investigação é algo maior que a reflexão, e acredito que nem todo mundo que é reflexivo está necessariamente assumindo a investigação como postura" (COCHRAN-SMITH apud FIORENTINE e CRECCI, 2016). Segundo a autora, o significado cotidiano de refletir ou de reflexão significa ser pensativo, pensar sobre as coisas, prestar atenção. A investigação inclui isso e inclui também uma gama maior de atividades, como por exemplo, a sistematização sobre o que se está refletindo.

O mesmo ocorre com relação ao "professor-pesquisador". É inegável a importância da pesquisa do professor sobre

\footnotetext{
3 Para Cochran-Smith e Lytle (1999, 2002) o "conhecimento local" nasce na prática e a partir dela. É o conhecimento gerado pelos professores através de sua artesania, assim se relaciona ao saber-em-ação.
} 
o trabalho docente, no entanto seja vinculada a grupos de pesquisa na escolabásica (como vemos em alguns colégios federais) ou a universidade (como em pesquisa de mestrado ou doutorado), essas pesquisas são pontuais: tem iníciomeio-fim. Essas pesquisas são muito legítimas para a geração de conhecimento, "quando professores olham para suas próprias práticas, questionando seus próprios pressupostos e interrogando os arranjos escolares, eles habilitam-se a produzir, aumentar e alterar os conhecimentos que são úteis para sua comunidade local, e também para além dela" (COCHRANSMITH apud FIORENTINE e CRECI, 2016).

No entanto, Cochran-Smith e Lytle (1999) afirmam que ter a investigação como postura na formação docente é diferente de uma noção mais comum de investigação como sendo um projeto limitado no tempo, ou uma atividade discreta dentro de um curso de formação de professores ou uma oficina de desenvolvimento profissional. Para as autoras, os professores que já exercem a função e os professores em formação que assumem uma postura de investigação podem trabaIhar coletivamente para gerar conhecimento local, teorizar sobre sua prática, interpretar e questionar a teoria e a pesquisa de outros.

Acreditamos em uma formação de professores que esteja centrada no trabaIho docente, para além de uma mera contemplação dos fazeres de outros ou de experimentações vazias, mas sim da problematização e da investigação sobre a docência a partir do que ela é e de quem a faz: os professores. Dessa forma, a investigação como postura constitui uma estratégia de formação inicial que pode ajudar a desenvolver a capacidade de contínuo questionamento da prática e dos contextos onde essa se insere, contribuindo para que os professores aprendam sobre a docência ao investigarem sobre o que os constitui como docentes: seu trabalho.

Para isso é indispensável a participação de professores que já atuam na escola-básica em processos de formação inicial de outros docentes. Os futuros professores, em sua preparação na universidade, se beneficiarão com a convivência com esse trabalho, pelo qual podem conhecer de perto possibilidades e limites e ainda caminhos já traçados pela prática de professores experientes. Assim, a investigação poderia integra-se na prática cotidiana dos professores possibilitando mudanças no seu pensamento e na natureza do seu discurso favorecendo uma postura crítica face à sua profissão.

Acreditamos que constituir-se professor é um processo de construir, interrogar, elaborar e criticar os enfoques conceituais presentes no dia-a-dia da sala de aula. É um processo de construir uma identidade docente através da desconstrução constante, da problematização, da indagação e do inconformismo diante do cotidiano escolar em movimentos coletivos de investigação sobre a prática, sobre o trabalho docente, sobre o ser professor.

Neste processo está implícito um conjunto de questões que funcionam como lentes para ver e dar significado à prática construída: Quem sou eu como professor? Que estou presumindo sobre esta criança, este grupo, esta comunidade? Que sentido meus alunos dão ao que acontece na sala? Que estou tentando fazer acontecer aqui e por quê? Assim, os saberes possíveis de serem construídos, na dimensão formativa que acontece na escola - no trabalho, estão diretamente vinculados à atuação profissional do professor que, além de saber, numa dimensão mais teórica, precisa aprender a fazer e analisar esse saber fazer para que sua prática profissional seja sempre transformada e transformadora. 
e-Mosaicos - Revista Multidisciplinar de Ensino, Pesquisa, Extensão e Cultura do Instituto de Aplicação Fernando Rodrigues da Silveira (CAp-UERJ)

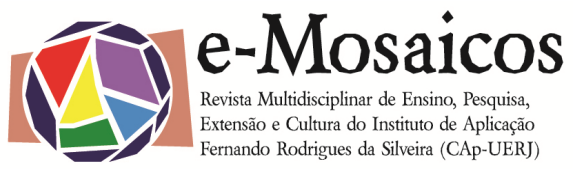

\section{APRENDIZAGEM DA DOCÊNCIA E O DESEN- VOLVIMENTO DE UMA POSTURA INVESTIGA- TIVA NO PIBID}

Ao estudarmos o caso do PIBID Pedagogia, percebemos o quanto as ações desenvolvidas no projeto incentivaram nos pibidianos o desenvolvimento de uma postura investigativa. Tal como observamos, ao preconizar a construção de conhecimento sobre a docência por meio da troca e do diálogo a partir do estímulo à reflexão sobre as experiências que compartiIhavam, as professoras supervisoras incutiram nos pibidianos o hábito de questionar e problematizar o trabalho docente.

Aprendi a ler mais, a buscar mais informações, a construir ideias e formular perguntas. Comecei a questionar o que eu sabia e o quanto eu poderia contribuir para uma educação melhor (portfólio Pib $5)$.

Desde quando iniciei no PIBID até o presente momento, tenho a absoluta certeza que o meu crescimento e desenvolvimento foi muito significativo, amadureci em todos os aspectos, aprendi a ter um olhar pedagógico em $360^{\circ}$ (ou pelo menos tento), a refletir e desnaturalizar as minhas ações e as dos outros (portfólio Pib 11).

Além do mais, esta experiência está me ensinando a abandonar as generalizações, a lidar com as diversidades e especificidades de cada sujeito e a justificar e refletir de maneira crítica as minhas opiniões. Estou tendo a oportunidade de trilhar a minha formação pelo caminho de uma concepção de ensino que eu acredito, onde existe diálogo, troca, liberdade, autoria, criação e sujeitos ativos e pretendo fundamentar a minha docência considerando essas aprendizagens (portfólio Pib 1).
Ao intervirem junto aos pibidianos compartilhando experiências - e as colocando sob escrutínio, instigando a reflexão - tomando o ensino e o que acontece antes, durante e depois dele como problematizável, e estimulando a observação - permeando-a de análise crítica, as supervisoras contribuem para que os bolsistas desenvolvam uma postura investigativa. Para além da reflexão como característica inerente do trabalho docente - enquanto marcado por intelectualidade e racionalidade - estas intervenções das supervisoras imprimem nos licenciandos o entendimento da aprendizagem da docência como um processo contínuo que se faz na coletividade através da busca por respostas a questões que funcionam como lentes para ver e dar significado à prática construída.

Quando eu falo com os licenciandos, eu falo da minha prática. E nisso que eu falo da minha prática eu revejo essa prática o tempo inteiro. (...) Em alguns momentos os alunos trazem pra gente questões que nos fazem pensar, que às vezes nos questionam também. $\mathrm{Na}$ verdade, assim, sempre tem uma contribuição porque os meninos também estão em formação em coisas novas. Os questionamentos deles também nos provocam (entrevista Sup1).

Colocar-se como mediador entre conhecimentos acadêmicos e profissionais permite às professoras supervisoras a oportunidade de "desenvolvimento profissional", criando a necessidade de buscar novos conhecimentos para responder aos questionamentos trazidos pelos pibidianos. Ao problematizarem sobre o trabalho docente com eles, constroem conhecimento sobre a docência que repercute nas próprias práticas, pois como afirma CochranSmith (2012), aprender a ensinar leva tempo e nunca se esgota. 
Então quando você tem escuta, porque também o professor, supervisor, ele pode estar fechado no que ele acredita que é certo e não ouvir e não dar voz ao licenciando, tanto eu quanto eles aprendemos (entrevista Sup1).

Em situações em que a participação dos professores em programas de aprendizado é uma obrigação, ou quando este se dá de forma pré-programada, CochranSmith e Lytle (1999) afirmam que o aprendizado desses docentes se torna "simplesmente" desenvolvimento profissional - a produção de um projeto de crescimento individual restrito no espaço e no tempo. Quando isto acontece, o aprendizado de professores passa a ser um fim em si mesmo. Acrescentam ainda que enquanto as iniciativas de aprendizado do professor se enquadrarem nos compromissos de um distrito escolar, da gestão de um local, de revisão curricular, por exemplo, elas poderão ser consideradas, ao menos, compatíveis com os esforços de melhoria das escolas. Mas, quando as iniciativas do aprendizado de um professor se referem à prática reflexiva, melhoria do profissionalismo, e transformações sociais mais amplas que extrapolam a escolas e ao entendimento do trabalho docente como algo coletivo, elas podem ser consideradas "verdadeiramente" como desenvolvimento profissional (COCHRAN-SMITH e LYTLE, 1999).

Nesse sentido, tão importante quanto investigar ${ }^{4}$ a docência é investigar a docência coletivamente, entendendo que se aprende mais e melhor sobre o trabalho docente quando os professores - investi-

\footnotetext{
4 Investigar aqui neste contexto - tanto no que defendemos quanto no que observamos - não se relaciona necessariamente a pesquisa sistemática, no sentido de cientificidade e rigor acadêmico. Está muito mais próximo ao esforço coletivo (em pares) de responder a problemas intrínsecos à realidade do trabalho, pelo trabalho e para o trabalho.
}

gadores/investigados - expõem o que fazem dentro das salas de aula. No que se refere ao PIBID estudado, sobre esse movimento de problematizar e investigar o trabalho docente em grupos que congregam professores experientes e em formação inicial, Pib 14 diz que permite o desenvolvimento de ambos os atores "pois tanto os pibidianos levantam dúvidas e sugestões quanto os professores supervisores passam a refletir sobre sua prática docente, trazendo novas formas de ensinar" (relato de experiência Pib 14). Aqui se destaca o papel do professor supervisor como sendo aquele que corporifica o elo entre universidade e escola básica, como sendo aquele que aproxima os pibidianos com o trabalho docente pela via da escuta e do diálogo.

Eu sei que quando a gente trabalha no PIBID é diferente do estágio por que lá a gente tá sozinho, aqui a gente tem esse momento, a gente pode conversar sobre o que acontece, sobre os acertos, sobre os erros e também com o professor da escola na universidade, acho que assim, está me ajudando muito (comunicação oral Pib 3).

De acordo com a proposta do Projeto Pibid Pedagogia, no qual o futuro professor é inserido no campo de atuação, observando e agindo nele, a minha perspectiva do ensino na sala de aula, da minha prática, pode ser construída com uma base estruturada, acompanhada, coletiva, observada, questionada, o que me dá segurança para futuramente exercer essa profissão tão árdua, porém, tão prazerosa (portfólio Pib 11).

Todas as quintas-feiras à noite, estar com meus colegas falando sobre histórias, anseios, desejos, sobre a escola e o que acontece lá de maneira afetiva e solidária muito 


\section{Tive-Mosaicos \\ Revista Multidisciplinar de Ensino, Pesquisa, Extensão e Cultura do Instituto de Aplicação Fernando Rodrigues da Silveira (CAp-UERJ)}

me fez bem. A meu ver é fundamental para a formação docente o futuro professor sentir-se bem com o que está fazendo e sem dúvida o PIBID proporciona esses momentos dentro da academia (portfólio Pib 12).

O relacionamento de ensino/aprendizagem da docência que se dá entre os pibidianos e as supervisoras não ocorre de modo neutro e natural. Pelo contrário, é notoriamente marcado pelas distintas visões sobre formação inicial, sobre o que "quer se dar" e o "quer receber". No entanto, ficou claro que, a despeito dos antagonismos que ora se acentuavam e das diferentes formas de se relacionar que os sujeitos construíam, o compromisso com o desenvolvimento da docência não se perdia. O foco é o aprendizado da docência, a iniciação à docência, isso não é desconsiderado. A seriedade com que se assume esse lugar exige das supervisoras diversas mediações e intervenções, ora mais assertivas, ora mais propositivas - sempre em um ambiente de troca e diálogo.

Soma-se a isso a necessidade de as professoras supervisoras encontrarem 0 equilíbrio entre a responsabilidade com a formação de seus alunos e a formação dos pibidianos com os quais precisam dividir atenção. É nesse papel de professor híbrido (ZEICHNER, 2010) e nos dilemas que ele suscita que percebemos as sutilezas de ser um professor supervisor.

Ter professores, em formação e experientes, reunidos ao redor de um objetivo em geral permite que os participantes aprendam novos papeis, que são conectados a novos conhecimentos e habilidades. Nesse sentido, não é simplesmente aprendizagem o que acontece, mas - já que saber e ser estão intimamente conectados um ao outro - também formação identitária.
Neste primeiro ano como bolsista do Projeto PIBID tenho aprendido muito sobre a importância da busca constante de aperfeiçoamento por parte do professor para que sua prática esteja sempre atualizada (portfólio Pib 2).

E eu acho que das conquistas e dos aprendizados a maior é conseguir fazer uma autocrítica do que você está fazendo. Sabe, assim, de entender que existem formas diferentes de se fazer as mesmas coisas, eu acho que é na diferença que a gente se encontra (comunicação oral Pib 12).

Entrar em contato com o projeto PIBID aumentou o meu desejo por uma profissionalização mais especializada, qualificada, diferente e ousada. Ao discutir ideias, próximas ou diferentes das minhas, meus horizontes se alargam quanto às variadas possibilidades do ato de ensinar, que para mim é mais que transmitir conteúdos, é também agregar valores psicológicos, sociais e morais, despertar interesses e principalmente estimular o prazer pelo ato de aprender (relato de experiência Pib 13).

O desenvolvimento de uma postura investigativa é fundamental para compreender que a prática educacional não é simplesmente instrumental, no sentido de perceber como conseguir que as coisas sejam feitas, mas também, e tão importante quanto, é o sentido político e social da deliberação sobre o que deve ser feito, porque deve ser feito daquela maneira, por que fazê-lo, quem decide, e a quais interesses estão servindo (COCHRANSMITH, 2012). Aprender a docência é algo que acontece com o tempo, e isso acontece melhor quando professores em formação trabalham na companhia de professo- 
res mais experientes, que também continuam aprendendo a ensinar.

Lüdke e Boing (2012) sinalizam que "a crença de que 'o professor se faz a si mesmo', num esforço individual isolado, contribui fortemente para uma desvalorização da formação de futuros professores, da teoria educacional e da própria profissão docente" (2012, p.432). Os autores argumentam ainda que quando se isolam professores em formação e professores experientes em modelos formativos baseados na observação

o professor se apresenta, se revela constantemente aos seus alunos, mas estes não podem alcançar todo o conjunto de pensamentos, reflexões, elaborações, decisões e mesmo ações que precedem as atividades desenvolvidas pelos professores frente a seus alunos (LÜDKE e BOING, 2012, p.433).

Lüdke e Boing (2012) reconhecem que "a análise da atividade do professor vista assim de perto, em seu dia a dia, em sala de aula, com seus alunos, na escola, com seus colegas, oferece muitas oportunidades de conhecer o que realmente se passa e como se passa no trabalho do professor" (2012, p.447). O que importa aqui não é meramente observar, ou discutir o que se viu com outros que não viram, mas sim problematizar e investigar o trabalho docente com quem os faz: os professores. Promover o desenvolvimento de uma postura investigativa na formação inicial docente, tal como vimos no PIBID deste caso, possibilita ao professor forjarse em uma visão transformada e ampliada da prática.

Para Zeichner (2010, p. 483), "essa visão mais ampla sobre os diferentes saberes, que são necessários para formar professores, expande as oportunidades de aprendizagem docente na medida em que novas sinergias são criadas por meio do jogo interativo entre conhecimentos das mais diferentes fontes". Para Pib 14, o PIBID UFRJ Pedagogia "prioriza a construção coletiva, situações de interação com diversos grupos, na Escola Básica ou na própria Universidade. $O$ projeto favorece a troca de experiências com diferentes sujeitos que possuem vivências, culturas e relatos distintos" (relato de experiência Pib 14).

Assim, pela via da parceria universidade-escola básica e da conexão entre conhecimentos profissionais e acadêmicos, espera-se contribuir na construção dos conhecimentos necessário para a formação de pedagogos docentes. Conhecimentos estes baseados na premissa de que ensinar é uma atividade contextualmente situada, que não é neutra e que está distante do improviso. Através da problematização e da investigação sobre o trabalho docente com professores da escola básica pretende-se fortalecer a ação dos professores numa abordagem crítica e contextualizada, "que conecta ação e problema no contexto imediato a questões sociais, culturais e políticas mais amplas" (COCHRANSMITH e LYTLE, 1999).

\section{CONCLUSÕES}

Os dados nos mostram que há os pibidianos o desenvolvimento de uma postura investigativa, percebemos o quanto o "questionar a realidade dada" é presente nas ações do PIBID investigado.

Ainda que as ações do PIBID Pedagogia se desenvolvam através de processos de problematização e investigação sobre o trabalho docente, ele não se destina a este fim. Vinculando-se exclusivamente a aprendizagem da docência (e ao ensino dela), é para isso que é procurado. Professoras supervisoras e pibidianos não têm intenção de problematizar e investigar o que acontece na escola. Observamos que quando o fazem é naturalmente, mui- 


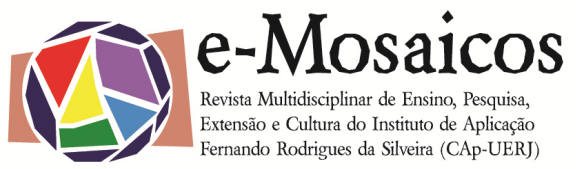

tas vezes sem ao menos perceberem. Isto incide diretamente no fato de que problematizar e investigar o trabalho docente é estimulado (pela estrutura do programa estudado), de fato acontece, mas não se concretiza por tangenciar as ações circunstancialmente.

Quanto a isso, verificamos que o PIBID investigado nunca se destinou a fazer pesquisa sobre a docência, mas que a problematização e a investigação sobre o trabalho docente permeiam as ações ali desenvolvidas. Sendo um grupo de ensinoaprendizagem sobre a docência, se preocupa em formar professores e não pesquisadores, mas pelas intervenções das supervisoras e pela maneira como as aproximações entre elas e os pibidianos se deram, criou-se um ambiente de questionamento, indagação, exposição de dúvida e proposição de (possíveis) respostas. Sendo assim, ainda que percebamos nos pibidianos o desenvolvimento de uma postura investigativa, de fato ela se mostrou muito ligada aos questionamentos que eles faziam às professoras supervisoras. Assim, as supervisoras se configuram como as suscitadoras das perguntas e das respostas dos pibidianos, que ainda não têm condições plenas para fazerem conexões mais amplas entre o que acontece na sala de aula onde estão alocados e a escola como um todo (menos ainda quando se fala de escolas).

Ainda que as aprendizagens construídas sejam notórias, os dados nos mostram também o quanto isto é um processo em construção, cujas consequências começam a se consolidar em um movimento vivo que avança e retrocede nos sujeitos envolvidos pelas próprias ações deles, pelos significados que se forjam diante das experiências vividas. Acreditamos que 0 desenvolvimento de uma postura investigativa apenas começou, não temos certeza se será consolidada em todos os sujeitos envolvidos, mas cremos que se assim o for será especialmente bom para o futu- ro exercício profissional dos pibidianos quando enfim forem professores (COCHRAN-SMITH e LYTLE 1999 e 2002).

\section{REFERÊNCIAS BIBLIOGRÁFICAS:}

ANDRÉ, M. E. D. A. Estudo de caso em pesquisa e avaliação educacional. Brasília: Liber livro, 2005.

. O que é um estudo de caso qualitativo em educação? Educação e Contemporaneidade, Salvador, v. 22, n. 40, p. 95-103, jul./dez, 2013.

COCHRAN-SMITH, M. Learning and unlearning: the education of teacher educators. 2001. In: Teaching and Teacher Education 19: 5-28. Lynch School of Education, Campion Hall 113, Boston College, Chestnut Hill, MA 02467, USA.

and S. L. Lytle. 1999. Relationships of knowledge and practice: Teacher learning in communities. In Review ofresearch in education, ed. A. Iran Nejad and P. D. Pearson, 24(1): 249-305. Washington, DC: American Educational Research Association.

and S. L. Lytle, 2002. Teacher Learning Communities. Encyclopedia of Education. 2 nd Edition. J. Guthrie (eds.). New York: Macmillan.

FIORENTINI, D.; CRECCI, V. Interlocuções com Marilyn Cochran-Smith sobre aprendizagem e pesquisa do professor em comunidades investigativas. Revista Brasileira de Educação, v. 21, n. 65, abr.-jun. 2016.

LÜDKE, M.; BOING, L. A. Do trabalho à Formação de Professores. Cadernos de Pesquisa, v.42 n.146 p.428-451 maio/ago. 2012. 
MOREIRA, A. F. B. Currículo, cultura e formação de Professores. Educar, Curitiba, n. 17, p. 39-52. 2001. Editora da UFPR.

NÓVOA, A. Para uma formação de professores construída dentro da profissão. In: Professores: imagens do futuro presente. Lisboa: Educa, 2009. p. 25-46.

ROLDÃO, M. do C.. Função Docente: natureza e construção do conhecimento profissional. Revista Brasileira de Educação. V. 12 n. 34 jan./abr. 2007.

YIN, R. K. Estudo de caso: planejamento e métodos. Porto Alegre: Bookman, 2010.

ZEICHNER, K. M. Repensando as conexões entre a formação na universidade e as experiências de campo na formação de professores em faculdades e universidades. Educação, Santa Maria, v. 35, n. 3, p. 479-504, set./dez. 2010. 